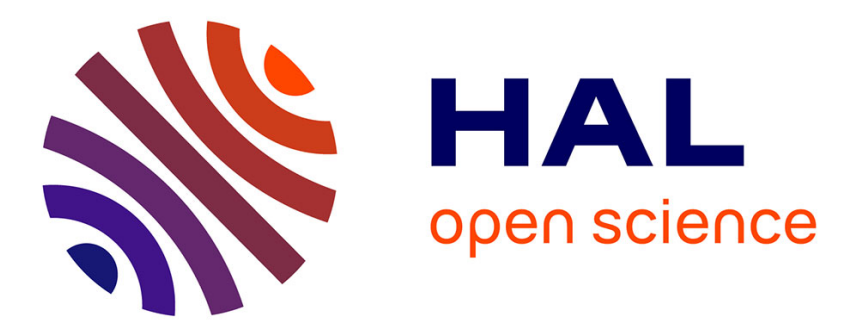

\title{
Clayey-sand filter for the removal of pharmaceuticals from wastewater effluent: Percolation experiments
}

Thomas Thiebault, Mohammed Boussafir, Régis Guégan, Claude Le Milbeau, Lydie Le Forestier

\section{- To cite this version:}

Thomas Thiebault, Mohammed Boussafir, Régis Guégan, Claude Le Milbeau, Lydie Le Forestier. Clayey-sand filter for the removal of pharmaceuticals from wastewater effluent: Percolation experiments. Environmental Science: Water Research and Technology, 2016, 2, pp.529-538. 10.1039/C6EW00034G . insu-01298757

\section{HAL Id: insu-01298757 https://hal-insu.archives-ouvertes.fr/insu-01298757}

Submitted on 6 Apr 2016

HAL is a multi-disciplinary open access archive for the deposit and dissemination of scientific research documents, whether they are published or not. The documents may come from teaching and research institutions in France or abroad, or from public or private research centers.
L'archive ouverte pluridisciplinaire HAL, est destinée au dépôt et à la diffusion de documents scientifiques de niveau recherche, publiés ou non, émanant des établissements d'enseignement et de recherche français ou étrangers, des laboratoires publics ou privés. 


\section{Journal Name}

\section{ARTICLE}

\section{Clayey-sand filter for the pharmaceuticals removal from wastewater effluent: Percolation experiments}

Received 00th January 20xx, Accepted 00th January 20xx

DOI: $10.1039 / x 0 x x 00000 x$

www.rsc.org/

\author{
T. Thiebault, ${ }^{* a}$ M. Boussafir, ${ }^{a}$ R. Guégan, ${ }^{a}$ C. Le Milbeau ${ }^{a}$ and L. Le Forestier ${ }^{a}$
}

\begin{abstract}
The objective of the study was to evaluate the sorption of a pool of pharmaceutically active compounds (PhACs) onto a clay-sand filter in a dynamic sorption experiment. The chosen adsorbent should have suitable chemical properties for the removal of the targeted PhACs and also consistent hydrodynamic behavior regarding field application. In this aim, the impact of interfoliar cation $\left(\mathrm{Ca}^{2+}\right.$ or $\left.\mathrm{Na}^{+}\right)$intercalated into natural montmorillonite (Swy2) was tested by using different clay-sand ratios (from $0 \%$ to $100 \%$ of clay minerals). Only Ca-Swy 2 showed a consistent hydraulic conductivity for field application with a value of $4.78 \times 10^{-8} \mathrm{~m} . \mathrm{s}^{-1}$ for $5 \%-95 \%$ clay-sand ratio. The sorption of PhACs onto this filter was investigated using œdometer cells by varying two parameters, the solution matrix (ultra-pure water or natural effluent) and the injection pressure (0.1 MPa and 0.2 MPa). PhACs were effectively adsorbed onto the filter for each experiment at different levels. The drop in injection pressure was a favorable factor for sorption whatever the matrix, with median global removal of $\sim 45 \%$ at $0.2 \mathrm{MPa}$ and $\sim 75 \%$ at $0.1 \mathrm{Mpa}$. The effect of the matrix exhibited two different trends as a function of the molecular charge of each PhAC. While cationic compounds were more effectively sorbed in the ultra-pure water matrix than in effluent matrix the sorption of anionic PhACs was more effective in the effluent matrix than in ultra-pure water. This indicates that the charge of the pollutant is a key parameter controlling the efficiency of the adsorbent. Despite these removal variations, the filter exhibited a significant sorption capacity especially at $0.1 \mathrm{MPa}$. It can therefore be an efficient solution for the removal of PhACs by tertiary filtration.
\end{abstract}

\section{Introduction}

2 Emerging Pollutants (EPs) represent a common form of pollution in numerous water compartments, from effluents to drinking water. Pharmaceutically Active Compounds (PhACs) account for more than 3,000 compounds among the most concentrated and persistent ones in the environment. ${ }^{1,2}$ They constitute a representative part of EPs due to their wide variety of chemical properties. ${ }^{3,4}$

Ever since the study by Richardson and Bowron highlighting the fate of pharmaceutical residues in the environment, $^{5}$ several investigations have been conducted in this field over the last thirty years. Studies have focused on the removal of PhACs in Waste-Water Treatment Plants (WWTPs), ${ }^{6,7}$ and on improving the sensitivity of analytical methods in order to better characterize their occurrence in the environment. ${ }^{8,9}$

There are three main types of WWTPs: activated sludge treatment plants, phytoplanted filters or lagoon-based a. Institut des Sciences de la Terre d'Orléans, UMR 7327 , Univ Orléans, CNRS, BRGM 42 1 A Rue de la Férollerie, 45071 Orléans, France. E-mail : thomas.thiebault@cnrs- 43 orleans.fr

+ Footnotes relating to the title and/or authors should appear here

Electronic Supplementary Information (ESI) available: [details of any 45 supplementary information available should be included here]. See DOI: $10.1039 / x 0 x x 00000 x$
20 systems, but the removal of EPs remains insufficient for 21 all of them. ${ }^{10-12}$ The main consequence of this lack of 22 efficiency is the constant discharge of PhACs into the 23 aquatic system. Even if PhACs are present in natural 24 waters at relatively low concentrations, from several $25 \mathrm{ng} \cdot \mathrm{L}^{-1}$ to $\mu \mathrm{g} \cdot \mathrm{L}^{-1},{ }^{4,13}$ their toxicity has been widely 26 proved, ${ }^{14,15}$ particularly for endocrine disruptors. ${ }^{16,17}$ 27 Moreover, some PhACs can be concentrated in natural 28 beings, $^{18}$ and contaminate the whole trophic chain 29 including humans with poorly-known consequences. ${ }^{19}$ 30 While this contamination goes beyond issues of human 31 health, it raises awareness of the hazards generated by 32 EPs and particularly PhACs.

33 Waste-water treatment is framed by two major factors, 34 purification capacity and cost. Numerous innovative 35 methods such as activated carbon or UV-oxidation 36 exhibit excellent results for the removal of EPs but are 37 often reserved for drinking water treatment due to

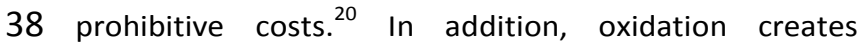
39 metabolites, ${ }^{21}$ whose toxicity is still unknown today.

40 Ali et al. showed by a simple calculation between several 41 removal techniques that adsorption mechanisms are the most appropriate and easiest way to remove both inorganic and organic micro-pollutants, ${ }^{22}$ since the adsorbent material has a large specific surface and a good affinity with the targeted micro-pollutants. ${ }^{23,24}$ 


\begin{tabular}{|c|c|c|c|c|c|c|c|}
\hline Drug & $\begin{array}{c}\text { Abbreviatio } \\
n\end{array}$ & CAS-Number & $\mathrm{M}_{w}$ & рKa & $\log \mathrm{K}_{\mathrm{ow}}$ & $S_{w}$ & Charge \\
\hline $\begin{array}{l}\text { Atenolol } \\
\mathrm{C}_{14} \mathrm{H}_{22} \mathrm{~N}_{2} \mathrm{O}_{3}\end{array}$ & ATE & 29122-68-7 & 266.34 & 9.6 & 0.16 & 300 & + \\
\hline $\begin{array}{l}\text { Codeine } \\
\mathrm{C}_{18} \mathrm{H}_{21} \mathrm{NO}_{3}\end{array}$ & COD & $76-57-3$ & 299.36 & 8.21 & 1.2 & $79 \times 10^{2}$ & + \\
\hline $\begin{array}{l}\text { Diazepam } \\
\mathrm{C}_{16} \mathrm{H}_{13} \mathrm{CIN}_{2} \mathrm{O}\end{array}$ & DIA & $439-14-5$ & 284.74 & 3.4 & 2.82 & 50 & 0 \\
\hline $\begin{array}{l}\text { Diclofenac } \\
\mathrm{C}_{14} \mathrm{H}_{11} \mathrm{Cl}_{2} \mathrm{NO}_{2}\end{array}$ & DCF & 15307-79-6 & 296.15 & 4.15 & 4.06 & $50 \times 10^{3}$ & - \\
\hline $\begin{array}{l}\text { Doxepin } \\
\mathrm{C}_{19} \mathrm{H}_{21} \mathrm{NO}\end{array}$ & DOX & $1229-29-4$ & 279.38 & 8.96 & 3.86 & $32 \times 10^{3}$ & + \\
\hline $\begin{array}{l}\text { Gemfibrozil } \\
\mathrm{C}_{15} \mathrm{H}_{22} \mathrm{O}_{3}\end{array}$ & GEM & $25812-30-0$ & 250.33 & 4.8 & 4.33 & 4.97 & - \\
\hline $\begin{array}{l}\text { Ibuprofen } \\
\mathrm{C}_{13} \mathrm{H}_{18} \mathrm{O}_{2}\end{array}$ & IBU & $15687-27-1$ & 206.28 & 4.91 & 3.72 & 21 & - \\
\hline $\begin{array}{l}\text { Ketoprofen } \\
\mathrm{C}_{16} \mathrm{H}_{14} \mathrm{O}_{3}\end{array}$ & KET & 22071-15-4 & 254.28 & 4.45 & 2.81 & 51 & - \\
\hline $\begin{array}{l}\text { Metoprolol } \\
\mathrm{C}_{15} \mathrm{H}_{25} \mathrm{NO}_{3}\end{array}$ & MET & 56392-17-7 & 267.36 & 9.6 & 1.79 & $47 \times 10^{2}$ & + \\
\hline $\begin{array}{l}\text { Naproxen } \\
\mathrm{C}_{14} \mathrm{H}_{14} \mathrm{O}_{3}\end{array}$ & NAP & 22204-53-1 & 230.26 & 4.15 & 3 & 15.9 & - \\
\hline $\begin{array}{l}\text { Oxazepam } \\
\mathrm{C}_{15} \mathrm{H}_{11} \mathrm{ClN}_{2} \mathrm{O}_{2}\end{array}$ & OXA & 604-75-1 & 286.97 & $\begin{array}{l}1.7- \\
11.6\end{array}$ & 2.31 & 20.71 & 0 \\
\hline $\begin{array}{l}\text { Progesterone } \\
\mathrm{C}_{21} \mathrm{H}_{30} \mathrm{O}_{2}\end{array}$ & PRO & $57-83-0$ & 314.46 & - & 4.04 & 8.81 & 0 \\
\hline $\begin{array}{l}\text { Tramadol } \\
\mathrm{C}_{16} \mathrm{H}_{25} \mathrm{NO}_{2}\end{array}$ & TRA & $27203-92-5$ & 263.37 & 9.41 & 2.51 & $75 \times 10^{3}$ & + \\
\hline $\begin{array}{l}\text { Trimethoprim } \\
\mathrm{C}_{14} \mathrm{H}_{18} \mathrm{~N}_{4} \mathrm{O}_{3}\end{array}$ & TRI & 738-70-5 & 290.32 & 7.2 & 0.38 & 400 & 0 \\
\hline
\end{tabular}

With $M_{w}$, the molecular weight in g.mol ${ }^{-1}$, pKa the acid dissociation constant, log $K_{\text {ow }}$ the octanol/water partition coefficient, $S_{w}$ the solubility in water at $25^{\circ} \mathrm{C}$ in $\mathrm{mg} . \mathrm{L}^{-1}$ and Charge, the dominant form at $\mathrm{pH}=7$

Table 1: Selected pollutants and parameters used in this work

Natural materials such as clays offer a good balance between reactivity and cost for the treatment of effluents. ${ }^{25}$ The efficiency of clays CEC (Cationic

Exchange Capacity) in water is well documented. ${ }^{26-28}$ After all, numerous PhACs are not in cationic form but in neutral or anionic form in environmental conditions. Another key parameter is the influence of the solid-liquid ratio, which is often very remote from realistic applications. ${ }^{29,30}$ The latter two studies sought to gain a better understanding of sorption mechanisms for which starting concentrations are often largely overestimated compared to simulation approaching field conditions. To our knowledge, no study has investigated the sorption of PhACs at low starting concentrations (25 $\mu \mathrm{g} . \mathrm{L}^{-1}$ ) onto natural clays. However sorption experiments with PhAC concentrations that are as close as possible to those found in natural environments and water purification plants are necessary in order to estimate the efficiency of sand and clay mixtures and the real affinities between the tested materials and the targeted pollutants.

A similar concern also frames the choice of the geosorbents and their characteristics as interlayer cation, which controls the sorption capacity and hydrodynamic behavior. ${ }^{31,32}$

In view of the well-established capacity of clays to remove numerous compounds from water, the present study addressed three main issues: (i) the real capacity of slightly modified clay to treat a complex solution in pure water or effluent (ii) the impact of the kinetic transfer and the matrix effect on the sorption and (iii)
77 the feasibility of a clay-based filter for the removal of 78 PhACs.

\section{Materials and Methods}

\section{Filter: clay minerals and sand}

81 The sand used was uniformly fine-grained Fontainebleau 82 quartz sand (from the Paris basin, France) of analytical 83 grade, and with a granulometry of 100-150 MESH.

84 The clay mineral chosen was Swy2 Wyoming 85 montmorillonite (Crook County Wyoming, United

86 States), supplied by the Source Clays Repository of the 87 Clay Minerals Society. After $<2 \mu \mathrm{m}$ fractionation by 88 gravity sedimentation, the Swy2 sample was $\mathrm{Na}$ 89 exchanged by well-established procedures. ${ }^{33}$ This $\mathrm{Na}$ -

90 Swy2 was the starting material for the production of $\mathrm{Ca}$ -

91 Swy2 with the same procedure, by replacing $\mathrm{NaCl}$ with

$92 \mathrm{CaCl}_{2}$. These two interlayer cations were chosen because 93 of their predominance in the environment.

94 Different proportions of sand and clay were tested to 95 estimate the hydrodynamic properties of the resulting $96 \mathrm{mix}$, with clay percentage in the filter of $5 \%, 10 \%, 50 \%$ 97 and $100 \%$ (i.e. pure clay) and with a constant total mass 98 of $8.0 \pm 0.4 \mathrm{~g}$. For percolation tests with PhACs, a $5 \%$ clay 99 filter was used.

\section{PhACs and chemical reagents}

101 The 14 PhAC standards (purity grade $>98 \%$; see Table 1 102 for details) were obtained from Sigma-Aldrich for ATE, 103 COD, DIA, DOX (Doxepin Hydrochloride), GEM, KET, MET 104 (Metoprolol Tartrate salt), NAP, OXA, PRO, TRA 105 (Tramadol Hydrochloride), TRI, and from Acros Organics 106 for DCF (Diclofenac Sodium) and IBU. 
Chemical reagents of analytical grade, methanol ( $\mathrm{MeOH})$ and pyridine were purchased from Fisher Scientific. $\mathrm{N}$ tert-Butyldimethylsilyl-N-methyltrifluoroacetamide (MTBSTFA, >95\%) was supplied by Sigma-Aldrich.

\section{Percolation Experiments}

Percolation experiments were carried out in œdometer cells. This specific equipment was developed to understand the hydrodynamic behavior of a solid sample under different conditions. ${ }^{34}$

The œdometer cell (internal diameter $=0.04 \mathrm{~m}$ ) and the injection syringe were both connected to a distinct compressed-air system in order to apply respectively the mechanical pressure on the sorbent material and the injection pressure on the leaching solution. The equipment scheme and further details are given in Figure S1 and in Gautier et al. ${ }^{35}$

For each experiment, $8 \mathrm{~g}$ of material (clay-sand mix) was gradually compacted on the bottom side up to $0.5 \mathrm{MPa}$, then totally unloaded, and compacted again at a mechanical pressure of $0.3 \mathrm{MPa}$. The solution was injected at the upper side into this compacted sample at a constant pressure during experiments. The injection pressure is the variable which controls the interaction kinetic between the solution and the material. Indeed, œdometer cells enable physical and hydraulic properties to be jointly controlled. Two different injection pressures were used in this study, 0.1 and $0.2 \mathrm{MPa}$.

In order to control impact of the matrix on the adsorption of PhACs, two solutions were used in the experiments: (i) a mix, hereafter called $S$, of each of the 14 selected PhACs at concentrations around $25 \mu \mathrm{g} \cdot \mathrm{L}^{-1}$ in ultra-pure water, and (ii) a mix between the 14 PhACs and an effluent of a French rural WWTP, called N. Although PhACs were present in this effluent their maximum concentration around $200 \mathrm{ng} . \mathrm{L}^{-1}$ did not affect our results by modifying starting concentrations noticeably (Table S1 for details, and Table S2 for the chemical parameters of the chosen effluent).

The choice of the starting concentration at $25 \mu \mathrm{g} \cdot \mathrm{L}^{-1}$ for each PhAC corresponds to the maximum PhAC concentrations in some effluents. ${ }^{13}$

During percolation experiments, leachate samples were collected each time that a volume of $100 \mathrm{~mL}$ solution passed through the filter. A total of $1 \mathrm{~L}(10 \times 100 \mathrm{~mL})$ was therefore used for each percolation experiment.

\section{Leachate and clay analyses}

\section{Leachate analysis}

Leachate solutions were concentrated by Solid-Phase Extraction (SPE) and analyzed by Gas Chromatography coupled to Mass Spectrometry (GC-MS).

PhAC extraction was carried out on a $6 \mathrm{~mL}$ glass cartridge filled with HR-X phase (Macherey-Nagel). Cartridges were conditioned with $5 \mathrm{~mL}$ of $\mathrm{MeOH}$ then with $5 \mathrm{~mL}$ of ultra-pure water. Columns were filled with $100 \mathrm{~mL}$ of sample and then rinsed with $5 \mathrm{~mL}$ of ultra-pure water before drying for 30 minutes under vacuum. Finally,
163 elution was performed with $3 \times 5 \mathrm{~mL}$ of $\mathrm{MeOH}$.

164 Thereafter, internal standard was added to organic

165 layers, which were evaporated under reduced pressure.

166 Residues were derivatized with MTBSTFA according to

167 Schummer et al. ${ }^{36}$

168 Analyses were performed on a Trace GC Ultra gas 169 chromatograph (GC) coupled to a TSQ Quantum XLS 170 mass spectrometer equipped with an AS 3000 171 autosampler (both from Thermo Scientific). The GC was

172 fitted with a Thermo Trace Gold TG-5 MS capillary 173 column ( $60 \mathrm{~m}, 0.25 \mathrm{~mm}$ i.d., $0.25 \mu \mathrm{m}$ film thickness).

174 The temperature of the column was held at $50^{\circ} \mathrm{C}$ for 3 $175 \mathrm{~min}$, increased from 50 to $120^{\circ} \mathrm{C}$ at $30^{\circ} \mathrm{C} \cdot \mathrm{min}^{-1}$, and from 176120 to $310^{\circ} \mathrm{C}$ at $3^{\circ} \mathrm{C} . \mathrm{min}^{-1}$ with a final isothermal hold at $177310^{\circ} \mathrm{C}$ for $21 \mathrm{~min} .2 \mu \mathrm{L}$ of sample was injected in splitless 178 mode at $280^{\circ} \mathrm{C}$. Helium was the carrier gas $\left(1 \mathrm{~mL} \cdot \mathrm{min}^{-1}\right)$. 179 The mass spectrometer was operated in $\mathrm{El}$ mode at 70 $180 \mathrm{eV}$, from $\mathrm{m} / \mathrm{z} 50$ to 500 .

\section{Clay characterization and global carbon analysis}

182 X-ray diffraction (XRD) patterns were recorded between 1832 and $64^{\circ}(2 \theta)$ using a Thermo Electron ARL'XTRA 184 diffractometer equipped with a $\mathrm{Cu}$ anode $(\mathrm{Cu} K \alpha 1,2=$ 1851.5418 A) coupled with a Si(Li) solid detector. 186 Experimental measurement parameters were 10s 187 counting time per $0.04^{\circ} 2 \Theta$ step. The diffractograms were 188 performed with dry powder samples $\left(100^{\circ} \mathrm{C}\right.$ for $\left.24 \mathrm{~h}\right)$.

189 Fourier transform infrared (FTIR) measurements were 190 recorded in the range $650-4000 \mathrm{~cm}^{-1}$, using a Thermo 191 Nicolet 6700 FT spectrometer equipped with a 192 Deuterated Triglycine Sulfate (DTGS) detector and a 193 Nicolet Continuum microscope. The analyses were 194 performed in transmission mode and each spectrum was 195 the average of 256 scans collected at $2 \mathrm{~cm}^{-1}$ resolution.

196 Carbon and nitrogen analyses were performed on 197 powdered samples by using a Thermo Scientific Flash 1982000 organic analyzer assuming an analytical error of $1990.05 \%$.

200

\section{Data analysis}

202 To characterize the distribution of a compound between 203 a potential sorbent and the dissolved phase, the $\log K_{d}$ 204 parameter is often used. ${ }^{37}$ The computation 205 corresponding to its calculation is expressed as follows:

206 
ARTICLE

218 These equations are expressed in linear form by 219 equations (2)-(4) respectively:

$220 \log \left(q_{m}-q_{t}\right)=\log q_{\mathrm{m}}-\frac{k_{1}}{2.303} t$

$221 \frac{t}{q_{t}}=\frac{1}{k_{2} q_{\mathrm{m}}^{2}}+\frac{1}{q_{\mathrm{m}}} t$

$222 \log q_{t}=\log k_{b}+\frac{1}{n} \log t$

223 with $q_{t}$ the sorbed concentration in $\mu \mathrm{g} \cdot \mathrm{mg}^{-1}$ at the time $t$ 224 ( $\min ), q_{m}$ the pseudo-equilibrium sorbed concentration $225\left(\mu \mathrm{g} \cdot \mathrm{mg}^{-1}\right), k_{1}\left(\mathrm{~min}^{-1}\right), k_{2}\left(\mathrm{~g} \cdot \mathrm{g}^{-1} \cdot \mathrm{min}^{-1}\right)$ and $k_{b}\left(\mathrm{~g} \cdot \mathrm{g}^{-1} \cdot \mathrm{min}^{-1}\right)$ 226 respectively the first-order, the second-order and the 227 Bangham sorption rate constants.

228 Each equation is based on different assumptions:

\section{Results and discussion}

\section{Hydrodynamic properties}

243

244

Percolation experiments were first performed with water solution in order to determine the hydraulic conductivity $(\mathrm{K})$ of the different clay-sand materials. $\mathrm{K}$, expressed in $\mathrm{m}_{\mathrm{s}} \mathrm{s}^{-1}$, was calculated from Darcy's law, using the expression developed for a saturated

$249 K=\frac{Q}{i . S}$

250 where $Q$ is the measured volumetric flow rate $\left(\mathrm{m}^{3} \cdot \mathrm{s}^{-1}\right)$ at 251 the steady state, $i$ is the hydraulic gradient and $S$ is the 252 cross-sectional area of the œdometer cell $\left(\mathrm{m}^{2}\right)$.

253 For a potential environmental application, the clay-sand 254 filter should have hydrodynamic properties that 255 correspond to the hydraulic conductivities operable in 256 actual treatment installations, whereas clays are a 257 natural barrier used for example to trap nuclear 258 wastes. $^{40}$

\begin{tabular}{lllll}
\hline Clays & SSA & CEC & $\varepsilon_{\max }$ & $\Theta_{\max }$ \\
\hline Na-Swy2 & $45.4^{\mathrm{a}}$ & $85.0 \pm 2.7^{\mathrm{a}}$ & $37 \%^{\mathrm{a}}$ & $75 \%$ \\
Ca-Swy2 & $46.0^{\mathrm{b}}$ & $85.1 \pm 0.01^{\mathrm{b}}$ & $1.5 \%$ & $62 \%$
\end{tabular}

With SSA, Specific Surface Area $\left(\mathrm{m}^{2} \cdot \mathrm{g}^{-1}\right) ; \mathrm{CEC}$, Cationic Exchange Capacity (meq.100 $\mathrm{g}^{-1}$ of clays); $\varepsilon_{\max }$ the maximum axial swelling strain for $100 \%$ clay sample; $\Theta_{\max }$ the maximum water content for $100 \%$ clay sample and ${ }^{a 33641}$

259 Table 2: Main properties of the selected clays saturated with $\mathrm{Na}^{+}$and $\mathrm{Ca}^{2+}$ as interfoliar cations

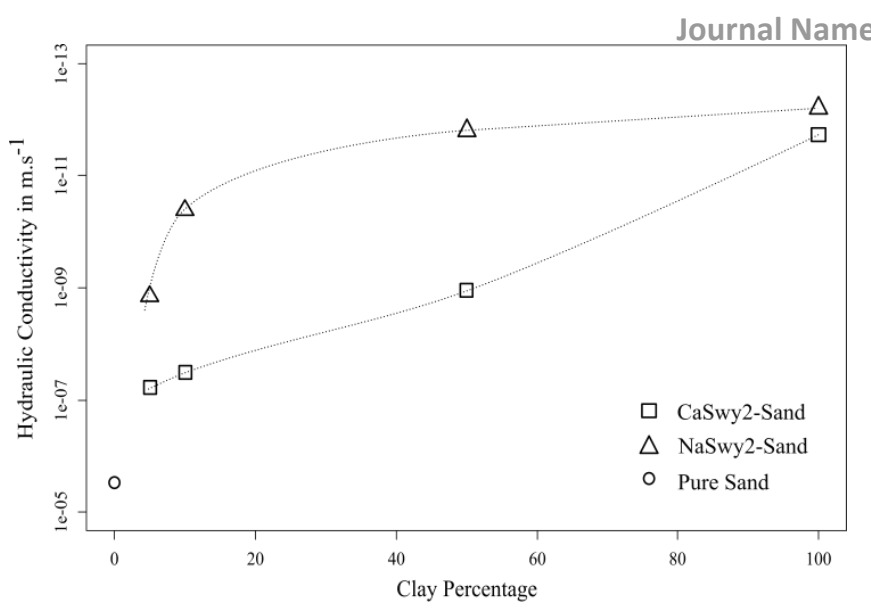

Figure 1: Hydraulic Conductivity as a function of the clay percentage in the claysand filter with circle: pure sand, triangles: clay-sand filters with Na-Swy 2 and squares: clay-sand filters with Ca-Swy2

261 This specific application should find a good balance between high permeable Fontainebleau sand and $\mathrm{Na}$ - or Ca-Swy2 clay with a low permeability.

Different clay-sand ratios were tested for both $\mathrm{Na}$ - and Ca-SWy2 in order to simulate and calculate the maximum flow of solution that can pass through the filter.

In accordance with the aim of this work, the ideal claysand ratio should include a low proportion of clay. As expected, the decrease in $\mathrm{K}$ was correlated with the finer texture related to the increase in clay percentage. Nevertheless, this evolution differed between the two clay materials tested (Figure 1):

- The NaSwy2-Sand mix can be considered as a waterproof material with $\mathrm{K}$ values between $1.35 \mathrm{e}^{-9} \mathrm{~m} . \mathrm{s}^{-1}$ (5\% clays) and $1.5 \mathrm{e}^{-12} \mathrm{~m} . \mathrm{s}^{-1}(50 \%$ clays)

- The CaSwy2-Sand mix allowed a better percolation at a low clay proportion with $\mathrm{K}$ between $4.76 \mathrm{e}^{-8} \mathrm{~m} . \mathrm{s}^{-1}$ (5\% clays) and $1.11 \mathrm{e}^{-9}$ $\mathrm{m} . \mathrm{s}^{-1}$ (50\% clays)

This permeability gap between the two materials can be explained by the differences in physico-chemical clay properties. Whereas the specific surface area and the cationic exchange capacity were similar for both $\mathrm{Na}$ - and Ca-Swy2 (Table 2), their macroscopic swelling performance varied greatly impacting their $\Theta_{\max }$ value.

\begin{tabular}{|c|c|c|c|c|}
\hline $\begin{array}{l}\text { Injection } \\
\text { Pressure }\end{array}$ & \multicolumn{2}{|c|}{$0.1 \mathrm{MPa}$} & \multicolumn{2}{|c|}{$0.2 \mathrm{MPa}$} \\
\hline Matrix & $\mathrm{S}$ & $\mathrm{N}$ & $S$ & $\mathrm{~N}$ \\
\hline Abbreviation & S1 & N1 & S2 & N2 \\
\hline Q & 9 & 9.1 & 17.9 & 18 \\
\hline $\begin{array}{c}\text { Filter } \\
\text { thickness } \\
(\mathrm{mm})\end{array}$ & 4.39 & 4.24 & 4.05 & 3.95 \\
\hline $\mathrm{pH}$ & 6.5 & 6.7 & 6.5 & 6.7 \\
\hline
\end{tabular}

Table 3 Experimental conditions for percolation experiments with PhACs in solution through a filter composed of $5 \%$ of Ca-Swy 2 and $95 \%$ of Fontainebleau sand 
292 The maximum axial swelling strain $\varepsilon_{\max }$, deduced from 293 the measured axial displacements of the piston, 294 revealed a high degree of swelling for the Na-Swy2 295 smectite compared to Ca-Swy2, 37\% and $1.5 \%$ 296 respectively (Table 2 ).

297 The high swelling capacity of Na-Swy2 influenced the 298 decrease in $K$ especially at a low clay percentage (5\%). 299 Conversely the extremely low macroscopic swelling for 300 Ca-Swy2 indicates a textural and crystalline swelling 301 control on the decrease in $K .5 \%$ was the clay proportion 302 selected for the percolation experiments with PhACs in 303 solution.

304 Ca-Swy2 presents another advantage compared to $\mathrm{Na}$ 305 Swy2 for a field use: the high macroscopic swelling 306 capacity of Na-Swy2 under wet conditions could damage 307 installations which are subjected to dry/wet cycles. 308 While the mechanical behavior of the Ca-Swy2 smectite 309 in association with sand was very similar to non-swelling 310 clay (such as kaolinites) with a low impact of dry/wet 311 cycles, this adsorbent was characterized by a high 312 specific surface area, making it suitable for interaction experiments with emerging organic pollutants.

In view of the very low permeability of the NaSwy2-sand mix, percolation experiments with the PhACs in solution were carried out only with CaSwy2-sand materials as filter. The experimental conditions for the percolation tests with a 5-95\% CaSwy2-sand mix are presented in Table 3.

\section{Drug Removal}

The global removal of the PhAC pool can be used to estimate the efficiency of the filter in different experimental conditions.

The term $\mathrm{C}_{0}$ was calculated by the addition of the initial concentrations of the $14 \mathrm{PhACs}$ and $\mathrm{C}$ corresponds to the addition of the $14 \mathrm{PhAC}$ concentrations for one collected sample.

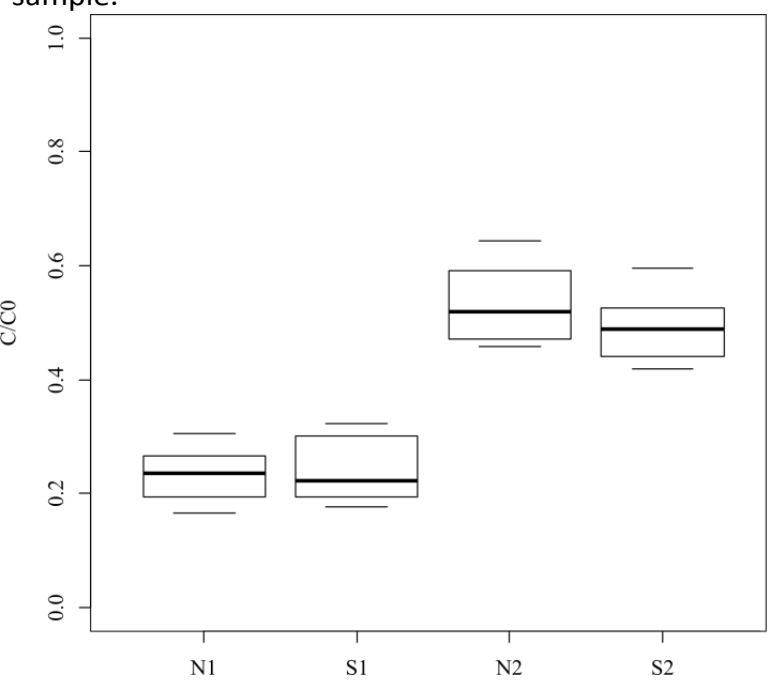

Figure 3: Additive sorption $\left(C / C_{0}\right)$ of all the pharmaceuticals for each experiment: boxes were computed from the removal values added for the 14 pollutants for 10 independent measurements. The line within the box marks the median, boundaries indicate the $25^{\text {th }}$ and $75^{\text {th }}$ percentiles, and error bars indicate the maximum and the minimum removal measurements

328 The spread of the ten values is around $10 \%$ of the total 329 removal (Figure 2) indicating a good regularity in the

330 sorption capacity of the tested material. The adsorption 331 capacity was significant (i.e. > 40\%) for all the 332 experimental conditions and the total removal reached 333 was between the extreme values of 35 and $85 \%$. No 334 significant differences in total $C / C_{0}$ in the global removal 335 were observed for the two matrices at the same 336 pressure $(p=.04$ and .06 at 0.1 and $0.2 \mathrm{MPa}$ 337 respectively). The median removal was around $75 \%$ at $3380.1 \mathrm{MPa}$ and $50 \%$ at $0.2 \mathrm{MPa}$ whatever the matrix. The 339 enrichment of the matrix with natural organic matter 340 (NOM) and electrolytes (matrix N) appeared to have no 341 impact on global removal whereas the drop in injection 342 pressure significantly enhanced removal $(p<.01$ between 343 N1 and N2 and between S1 and S2).

344 Partition and removal efficiency of targeted PhACs

345 The solid-liquid distribution coefficient $\left(K_{d}\right)$ is often used 346 to determine the ability of a material to sorb compounds 347 from a solution. This parameter was used to calculate 348 the partition between the solution and the sorbent for 349 each collected sample and estimate its variability 350 between the ten samples for each percolation 351 experiment. Unlike modeling equations of sorption 352 kinetic, the $K_{d}$ value does not directly depend on the 353 duration of the experiment.

354 Due to the chosen solid-liquid ratio, PhACs were half355 sorbed (50:50) if, $\log K_{d}=3.40{\mathrm{~L} . \mathrm{kg}^{-1}}$, and the starting 356 concentration is precisely $25 \mu \mathrm{g} \cdot \mathrm{L}^{-1}$.

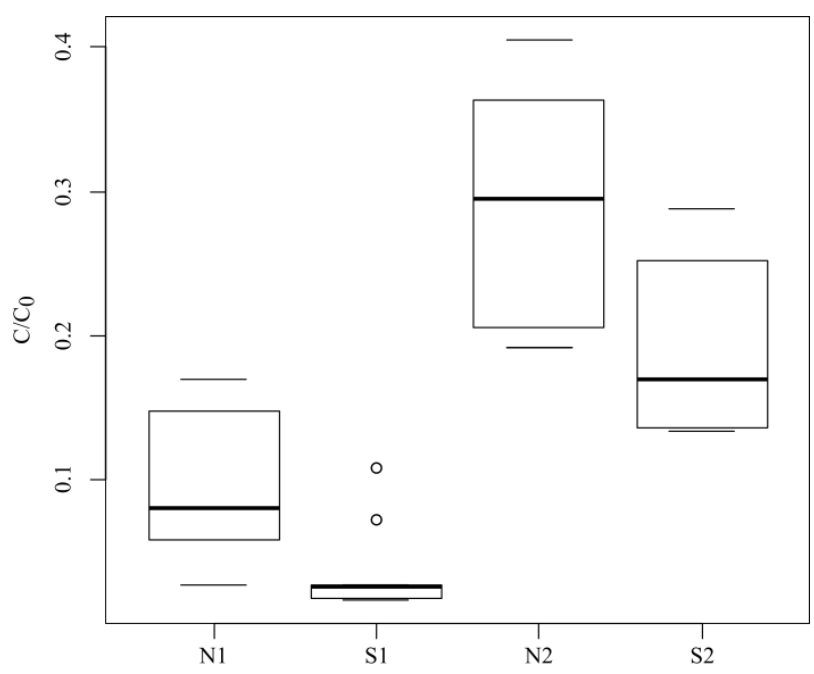

357 Figure 2: Additive sorption $\left(C / C_{0}\right)$ of the cationic pharmaceuticals for each

358 experiment: boxes were computed from the removal values added for the 14

359 pollutants for 10 independent measurements. The line within the box marks the 360 median, boundaries indicate the $25^{\text {th }}$ and $75^{\text {th }}$ percentiles, and error bars indicate 361 the maximum and the minimum removal measurements

\section{Cationic Species}

363 Two major trends emerged from the analysis of the total $364 \mathrm{C} / \mathrm{C}_{0}$ values for the cationic species (Figure 3 ).

365 The decrease in the injection pressure, corresponding to 366 a slowdown of the flux was a favorable factor for 367 sorption. For all the compounds, the transition from S2 368 to S1 was accompanied by a significant increase in the $369 \log K_{d} \quad(p<.01$ for the whole cationic compounds) 370 together with an increase in the total removal (Figure 3 ). 


\begin{tabular}{|c|c|c|c|c|c|c|c|c|c|}
\hline & \multicolumn{2}{|c|}{ S1 } & \multicolumn{2}{|c|}{ N1 } & \multicolumn{2}{|c|}{ S2 } & \multicolumn{2}{|c|}{ N2 } & \multirow{2}{*}{$\begin{array}{l}\text { onto Sludge } \\
\text { Log } K_{d}\end{array}$} \\
\hline & $\log K_{d}$ & MRv & $\log K_{d}$ & MRv & $\log K_{d}$ & MRv & $\log K_{d}$ & MRv & \\
\hline \multicolumn{10}{|c|}{ Cationic Species } \\
\hline ATE & $4.99 \pm 0.03$ & $97.0 \pm 0.04$ & $4.34 \pm 0.04$ & $87.6 \pm 0.09$ & $3.43 \pm 0.05$ & $46.2 \pm 0.41$ & $3.31 \pm 0.04$ & $37.2 \pm 0.39$ & $1.58^{\mathrm{a}}$ \\
\hline COD & $4.74 \pm 0.02$ & $95.2 \pm 0.03$ & $4.31 \pm 0.04$ & $88.6 \pm 0.11$ & $4.03 \pm 0.06$ & $73.2 \pm 0.24$ & $4.26 \pm 0.02$ & $86.4 \pm 0.09$ & $1.15^{\mathrm{a}, \mathrm{b}}$ \\
\hline DOX & $5.79 \pm 0.01$ & $99.6 \pm 0.01$ & $4.86 \pm 0.02$ & $96.2 \pm 0.03$ & $5.38 \pm 0.01$ & $98.9 \pm 0.01$ & $4.57 \pm 0.02$ & $93.2 \pm 0.03$ & $2.14^{\mathrm{b}}$ \\
\hline MET & $5.09 \pm 0.03$ & $96.9 \pm 0.03$ & $4.34 \pm 0.03$ & $89.0 \pm 0.08$ & $4.01 \pm 0.03$ & $77.2 \pm 0.16$ & $3.96 \pm 0.01$ & $75.8 \pm 0.12$ & $1.81^{\mathrm{b}}$ \\
\hline TRA & $4.63 \pm 0.03$ & $94.3 \pm 0.04$ & $3.96 \pm 0.04$ & $74.6 \pm 0.24$ & $3.94 \pm 0.02$ & $77.2 \pm 0.14$ & $3.65 \pm 0.02$ & $60.4 \pm 0.19$ & $1.67^{\mathrm{b}}$ \\
\hline TRI & $4.76 \pm 0.02$ & $95.3 \pm 0.06$ & $4.90 \pm 0.04$ & $96.4 \pm 0.03$ & $4.87 \pm 0.05$ & $95.0 \pm 0.04$ & $4.36 \pm 0.02$ & $91.4 \pm 0.07$ & $1.15^{b}$ \\
\hline \multicolumn{10}{|c|}{ Neutral Species } \\
\hline DIA & $4.20 \pm 0.03$ & $86.5 \pm 0.07$ & $4.19 \pm 0.03$ & $86.1 \pm 0.09$ & $3.45 \pm 0.04$ & $44.4 \pm 0.46$ & $4.33 \pm 0.04$ & $90.1 \pm 0.59$ & $1.72^{b}$ \\
\hline OXA & $3.78 \pm 0.01$ & $71.6 \pm 0.09$ & $3.84 \pm 0.01$ & $74.4 \pm 0.12$ & $2.01 \pm 0.13$ & $2.0 \pm 0.56$ & $3.17 \pm 0.01$ & $34.4 \pm 0.19$ & $1.11^{\mathrm{b}}$ \\
\hline PRO & $4.92 \pm 0.01$ & $97.4 \pm 0.01$ & $4.76 \pm 0.02$ & $96.1 \pm 0.03$ & $5.80 \pm 0.03$ & $99.5 \pm 0.01$ & $5.77 \pm 0.03$ & $99.6 \pm 0.01$ & $3.28^{\mathrm{a}}$ \\
\hline \multicolumn{10}{|c|}{ Anionic Species } \\
\hline DCF & $3.45 \pm 0.02$ & $55.3 \pm 0.12$ & $3.60 \pm 0.02$ & $59.8 \pm 0.19$ & $2.99 \pm 0.02$ & $26.2 \pm 0.35$ & $3.01 \pm 0.02$ & $28.9 \pm 0.36$ & $1.2^{c}$ \\
\hline GEM & $3.76 \pm 0.02$ & $71.6 \pm 0.09$ & $3.72 \pm 0.02$ & $67.2 \pm 0.18$ & $2.71 \pm 0.05$ & $13.9 \pm 0.72$ & $3.48 \pm 0.01$ & $52.6 \pm 0.16$ & $0.95^{\mathrm{a}}$ \\
\hline IBU & $3.07 \pm 0.02$ & $34.2 \pm 0.35$ & $3.35 \pm 0.01$ & $48.3 \pm 0.22$ & $2.08 \pm 0.04$ & $5.1 \pm 0.58$ & $2.61 \pm 0.04$ & $12.5 \pm 0.93$ & $2.23^{\mathrm{a}}$ \\
\hline KET & $4.11 \pm 0.04$ & $81.9 \pm 0.03$ & $4.12 \pm 0.02$ & $84.5 \pm 0.09$ & $3.44 \pm 0.04$ & $40.0 \pm 0.56$ & $3.99 \pm 0.01$ & $79.8 \pm 0.05$ & - \\
\hline NAP & $3.12 \pm 0.02$ & $40.4 \pm 0.29$ & $3.55 \pm 0.02$ & $53.7 \pm 0.41$ & $2.26 \pm 0.12$ & $6.1 \pm 0.86$ & $2.96 \pm 0.01$ & $24.5 \pm 0.27$ & $2.08^{a}$ \\
\hline
\end{tabular}

371 Table 4: $\log K_{d}$ values and Mean Removal values (in \%) for selected pollutants $372 \pm$ Relative Standard Deviation for each experiment, compared to Log $K_{d}$ values

373 found for PhACs onto sludge in the literature

374 Whereas for the S2 experiment, Log $K_{d}$ values varied 375 between ATE (3.43) and DOX (5.38), Log $K_{d}$ values were 376 more homogeneous for the S1 experiment (Table 4).

377 Whatever the injection pressure, the retention of 378 cationic PhACs was generally favored in the case of ultra379 pure water (S), except for TRI at $0.1 \mathrm{MPa}$ and COD at 0.2 $380 \mathrm{MPa}$ for which the opposite was recorded. The cationic 381 PhACs were probably in competition with other 382 components (organic or inorganic) contained in the wastewater effluent. As a result, the adsorption of cationic PhACs was lower in matrix $\mathrm{N}$ than $\mathrm{S}(p<.01$ for the two injection pressures).

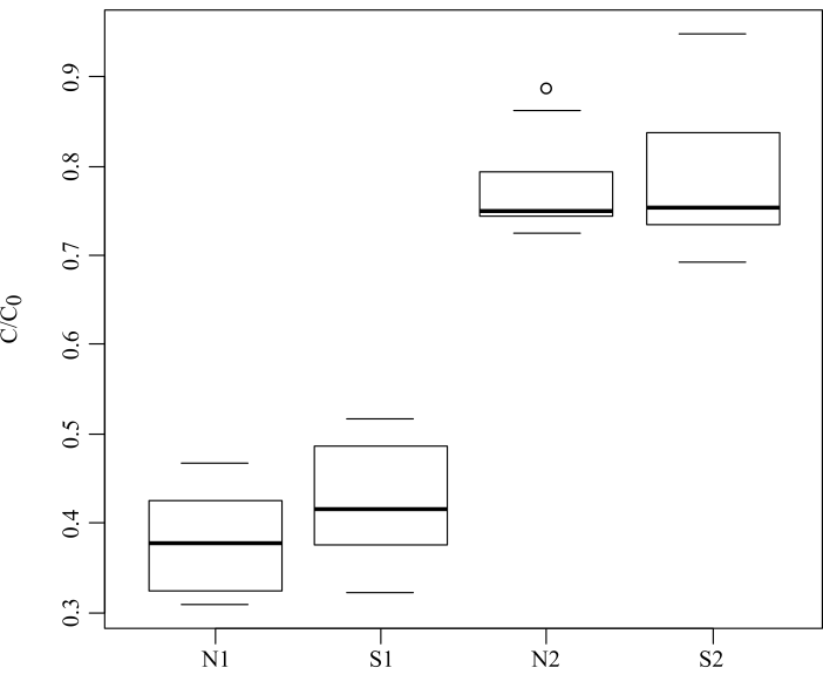

Figure 4: Additive sorption $\left(C / C_{0}\right)$ of the anionic pharmaceuticals for each experiment: boxes were computed from the removal values added for the 14 pollutants for 10 independent measurements. The line within the box marks the median, boundaries indicate the $25^{\text {th }}$ and $75^{\text {th }}$ percentiles, and error bars indicate the maximum and the minimum removal measurements

\section{Anionic species}

387 For anionic PhACs, the shift to a lower injection pressure 388 was also favorable for sorption (Figure 4), especially for 389 IBU in ultra-pure water (S2 vs S1) (Table 4). These results 390 indicated that the interaction kinetic is an important 391 component of the sorption, as for cationic PhACs.

392 The complexation of the matrix, especially at $0.2 \mathrm{MPa}$,

393 significantly increased the sorption of all the anionic 394 PhACs $(p<.01$ at 0.1 and $0.2 \mathrm{MPa})$. Between S1 and N1, 395 except for IBU, DCF and NAP (e.g. 3.10 to 3.54 396 respectively), the variations in Log $K_{d}$ values were not 397 statistically significant ( $p=.44$ and .36 for GEM and KET 398 respectively).

\section{Neutral Species}

401 The solid-liquid distribution variations for the three 402 neutral PhACs did not follow a trend. It was therefore 403 difficult to evaluate the impact of the matrix or of the 404 injection pressure. Whereas PRO was well sorbed 405 whatever the experimental conditions, for DIA and OXA, 406 variations in the $\log K_{d}$ values were closer to the 407 behavior of anionic species (Table 4).

\section{Partition control factors}

409 The effect of ionic strength or of the presence of organic matter in water, which can favor the sorption of anionic

411 species, was confirmed by the experimental results as 412 suggested in other studies. ${ }^{45}$ This assumption can be 413 explained by the adsorption of organic compounds or 414 electrolytes which could enhance the anionic sorption 415 capacities of the clay material. ${ }^{46}$

416 Kinetic transfer is the second major influence on the 417 sorption capacity. The sorption improvement is 418 particularly strong on anionic species, whose sorption 419 kinetic is known to be slower to reach equilibrium, ${ }^{47}$ 420 than that of cationic species (Figure 4). ${ }^{27}$

421 Measurements of Log $K_{d}$ values are generally performed 422 onto sludge to better understand the partition of PhACs 423 during waste-water treatment. ${ }^{42-44}$ Thus, sorption on 424 sludge can be considered as a removal despite the 
425 variable further use of sludge. If we compare the Log $K_{d}$ 426 values onto secondary sludge in the literature for each 427 compound (Table 4), there is no link between the charge 428 of the pollutant and the Log $K_{d}$. IBU or NAP are well 429 sorbed onto sludge whereas other anionic compounds 430 have a Log $K_{d}<2$. These compounds were also among 431 the three anionic compounds to be significantly better 432 sorbed in N matrix than S (Table 4) at 0.1 MPa. The 433 combination of these two factors demonstrated the
434
NOM impact on the sorption of some anionic PhACs.

For cationic species, only one value (for DOX) exceeds 2 and only the neutral compound PRO is well sorbed by sludge.

The affinity of our material with PhACs was far greater than that of sludge, with Log $K_{d}$ values up to at least for the $\mathrm{N} 1$ experiment, indicating that the chosen material has better trapping properties than sludge.

The greater complexity of sludge in terms of chemical reactivity results in a variable affinity with the targeted PhACs that does not depend only on the charge of the pollutants, ${ }^{48}$ whereas with clay material, the charge seems to play the most important role in the control of sorption.

\section{Sorption kinetics modeling}

Based on the obtained correlation coefficients of the three models tested that spread out from 0.90 to 0.999 (Tables S3, S4 and S5), it appears that the experimental data are better adjusted with Bangham equation $\left(r^{2}\right.$ comprised between 0.970 and 0.999). Nevertheless, the whole models used here provide similar trends. The efficiency of the adsorption is enhanced at high pressure 5 and 6 confirm and highlights the sorption rate was higher at $0.2 \mathrm{MPa}$ than at $0.1 \mathrm{MPa}$ indicating a better sorption efficiency at higher kinetic percolation.

The second-order Lagergren (Table S4) and Bangham (Table S5) equations suggested a good regularity of the deviation values expressed.

For the best sorbed compounds DOX, PRO and TRI, the comparison of $k_{2}$ and $q_{m}$ values indicated the same trends as those observed with the Log $K_{d}$ analysis on the matrix effect. An increase in log $k_{2}$ corresponding with a drop in $q_{m}$ between respectively $S$ and $N$ (for each injection pressure) indicated a matrix effect that was unfavorable for the adsorption of cationic compounds.

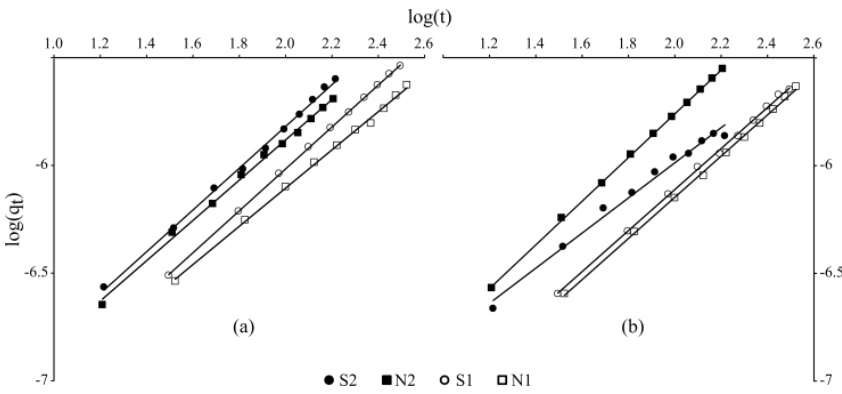

Figure 5: Bangham fits (solid lines) for (a) Tramadol (cationic) and (b) Ketoprofen (anionic) for each experiment as shown by $k_{1}$ constants (first-order Lagergen). Figures removal quality of the material as Log $K_{d}$ standard

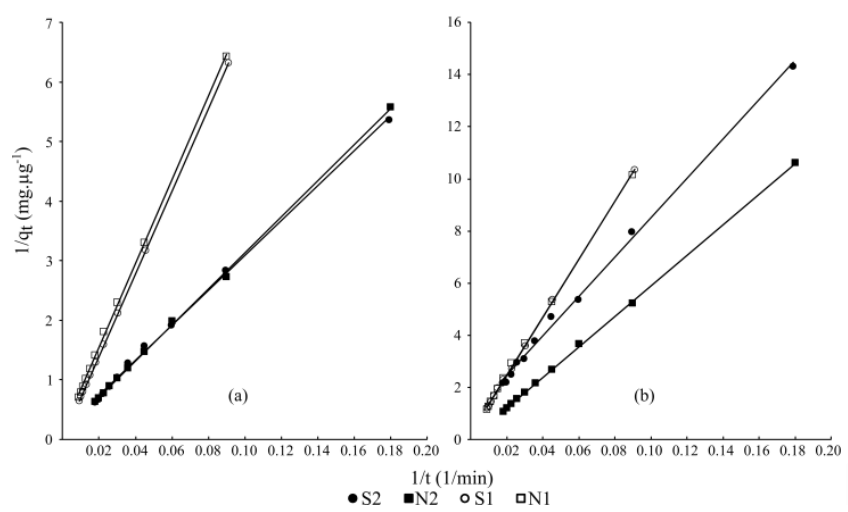

471 Figure 6: Pseudo second-order fits (solid lines) for (a) Metoprolol

472 (cationic) and (b) Diazepam (neutral) for each experiment 474 with a lower $\log k_{2}$ and a higher $q_{m}$ for $N$ than $S$. For the 475 other compounds, the data can be interpreted as shown

476 in Figure 5. For cationic species, there was a slight 477 unfavorable effect of the $\mathrm{N}$ matrix whereas the opposite 478 was observed for anionic species.

479 Unlike the Log $K_{d}$ values, the modeling and resulting 480 sorption efficiency values gave contrasting results. The 481 main controlling factor for the sorption capacity of Ca482 Swy2 towards PhACs is the chemical properties of the 483 molecule. As this material has a greater cationic than 484 anionic exchange capacity, cationic compounds were 485 strongly favored for sorption.

486 Otherwise, the sorption of anionic compounds was 487 slightly better in effluent matrix than in ultra-pure water 488 but it remained significantly lower than for cationic 489 compounds. This enhancement of anionic species 490 adsorption by the addition of NOM or electrolytes has 491 already been reported for IBU alone onto 492 montmorillonite, indicating that without a saturation 493 effect, the behavior of a pool of PhACs with Ca-Swy2 is similar to that of a single PhAC.

Model fittings demonstrated that Ca-Swy2 has a large sorption capacity spectrum even if the molecular charge remained a key factor for the removal ratio.

While the better removal efficiency at a lower injection pressure seemed to improve sorption, modeling results showed that the sorption rate was higher for higher injection pressures. With a view to optimizing the kinetic transfer through the filter, further data need to be obtained to combine the best removal efficiency with the best sorption rate constant.

\section{Clays characterization}

Clays were separated from sand after the leachate test for further characterization. Two methods were applied to investigate the adsorbent reaction to the leachate, $X R D$ and FTIR analysis.

$X R D$ and FTIR exhibited no significant layer expansion or band stretching respectively after experiments.

Elemental analyses were carried out on the clay minerals after the percolation of 1 liter in order to estimate the
473 The exact opposite was observed for IBU, OXA and NAP, 
514 total sorbed concentration based on the carbon 515 percentage of the clays (Figure 7).

516 The comparison between elemental analyses on clays 517 and leachate sample analyses exhibited similar results 518 for the ultra-pure water matrix. This is consistent with 519 the assumption that clays are responsible for most of 520 the sorption in comparison with sand. Similar results 521 between clays and water samples also indicated that 522 PhACs are effectively adsorbed onto Ca-Swy2 and not degraded furthermore.

In accordance with previous results obtained from solution analyses, the total sorbed concentration was higher for S1 than S2, with a total removal of $65.7 \%$ and $48.2 \%$ respectively.

For $\mathrm{N}$ matrices, the elemental analysis results are significantly higher than those of the leachate samples. This indicates that the material adsorbed more than PhACs from the effluent matrix. The additional organic compounds that were adsorbed may possibly explain the better sorption for anionic compounds in the effluents. ${ }^{49}$

\section{Sorption Mechanisms}

Despite the excellent removal efficiency of the prepared mineral mixture in this study, sorbed PhACs amounts remain low due to the selected starting concentrations that were $25 \mu \mathrm{g} \cdot \mathrm{L}^{-1}$. Since the sorbed amounts for the whole PhACs were rather low, it was rather hard to probe any changes through the use of classical analytical techniques such as FTIR or XRD, which may acknowledge us about conformation of molecules and their localization for a proper description of the adsorption processes.

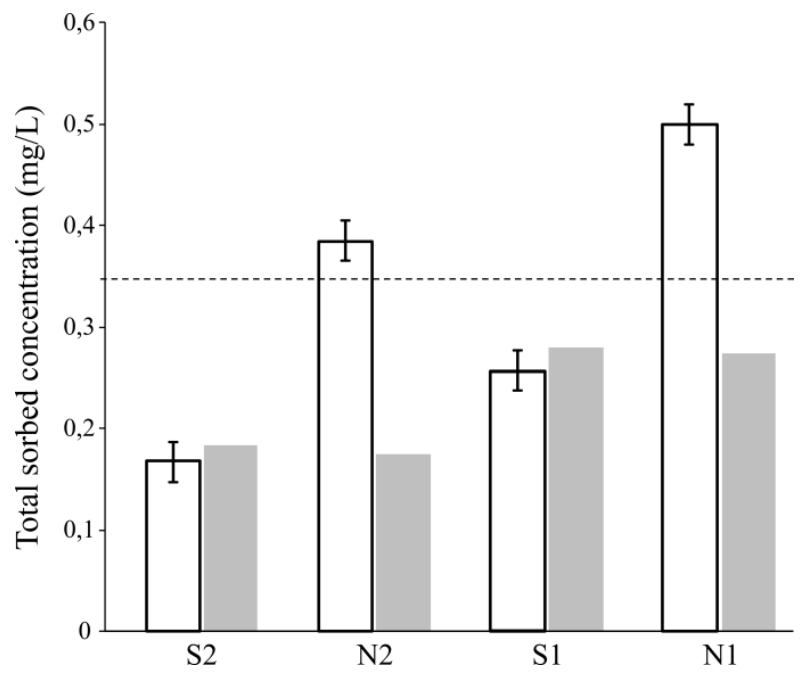

Figure 7: Comparison between the total sorbed concentrations calculated by elemental analysis of clays (white bars) and from the leachate samples (gray bars) for each percolation test. The dotted line corresponds to the total injected concentration of PhACs

545 Nevertheless, it appears that the sorption of anionic 546 PhACs is particularly enhanced for clay mineral with $\mathrm{Ca}^{2+}$ 547 as compensating cations. Indeed, $\mathrm{Ca}^{2+}$ is divalent and 548 showed its ability to sorb anionic species by cationic 549 bridges. $^{50}$ Here, the results suggest a better sorption 550 efficiency of anionic species in contrast to previous 551 studies using sodium exchanged Na-Swy2. ${ }^{49,51}$ However 552 electrostatic interactions or even hydrogen bonds cannot 553 be excluded that may play also as driving forces for the 554 adsorption. Further experiments need to be carried out 555 to better point out the sorption mechanisms.

556 Cationic species are usually adsorbed on clay mineral 557 through cation exchanges and it may also the case for 558 PhACs here. This mechanism is thermodynamically 559 spontaneous, ${ }^{27}$ but only compensating cations on the 560 external surfaces are involved since no changes in the 561 diffraction patterns were observed.

\section{Conclusions}

563

564

565

566

567

568

569

570

571

572

573

574

575

576

577

578

579

580

581

582

583

584

585

586

587

588

589

590

591

592

593

594

595

596

597

598

599
From the results of this study, the following conclusions can be drawn:

- Natural Ca-saturated smectite (Ca-Swy2) incorporated into a sand-filter allowed a flow consistent with in-situ applications whereas $\mathrm{Na}$ saturated smectite (Na-Swy2) is a waterproof material that is not adapted to the sorption of pollutants in a simulation of dynamic sorption close to field reality

- Ca-Swy2 exhibited a large adsorption capacity even for cationic, neutral and anionic PhACs at similar wastewater $\mathrm{pH}$. With the values of the relative standard deviation of samples, it seems that the sorption efficiency in time is steady. The sorption capacity is guided by two major parameters, infiltration kinetics and the composition of the matrix.

- The effluent matrix played a contrasting role on the sorption efficiency, depending on the molecular charge and the speciation at the tested $\mathrm{pH}$ : anionic species were favored by this complex matrix in contrast to cationic ones, for which the sorption efficiency was lower. Some NOM and/or electrolytes of the effluent were also adsorbed onto the filter and played a key role in the sorption of anionic compounds whereas they were in competition with cationic species. Further analyses need to be carried out to characterize them.

The applied models fitted our data well, but due to the pseudo equilibrium that was reached, the calculated constants did not correspond to previous observations for all the models. However, even a low kinetic (0.1 MPa) favored sorption processes, and at higher injection pressure sorption processes were more efficient 


\section{Acknowledgements}

620

\section{Notes and references}

627

628 of the filter. carbon analysis. 1999, 107, 907. 1985, 37, 1-12. 2014, 184, 354-359. 446, 22-28. 6475-6487.
Natural Ca-smectite is a slightly modified material that could significantly improve the removal efficiency of current treatment chains, especially concerning the removal of PhACs.

The key role played by the interlayer cation can direct the choice of geosorbent for further studies, using clays minerals that are naturally saturated by $\mathrm{Ca}^{2+}$, rather than by $\mathrm{Na}^{+}$ Implementation in the field of the tertiary treatment technique presented here requires further experiments. Nevertheless, this study stresses out the relevance of the material in a field application for a good removal efficiency especially in comparison with tertiary treatments using chemical products, potentially toxic for the environment. The main question now is the management costs induced by this technique, especially concerning the durability

The work received financial support from the HArPE Project (2012-00073536) funded by the Région CentreVal de Loire. The authors would also like to thank Fabrice Muller for XRD and FTIR analysis and Marielle Hatton for

1 C. G. Daughton and T. A. Ternes, Environ. Health Perspect.,

2 A. Masiá, J. Campo, P. Vázquez-Roig, C. Blasco and Y. Picó, J. Hazard. Mater., 2013, 263, Part 1, 95-104.

3 T. Heberer, J. Hydrol., 2002, 266, 175-189.

4 R. Loos, B. M. Gawlik, G. Locoro, E. Rimaviciute, S. Contini and G. Bidoglio, Environ. Pollut., 2009, 157, 561-568.

5 M. L. Richardson and J. M. Bowron, J. Pharm. Pharmacol.,

6 T. A. Ternes, Water Res., 1998, 32, 3245-3260.

7 T. Heberer, Toxicol. Lett., 2002, 131, 5-17.

8 B. F. da Silva, A. Jelic, R. López-Serna, A. A. Mozeto, M. Petrovic and D. Barceló, Chemosphere, 2011, 85, 1331-1339.

9 P. Vazquez-Roig, V. Andreu, C. Blasco and Y. Picó, Sci. Total Environ., 2012, 440, 24-32.

10 M. S. Kostich, A. L. Batt and J. M. Lazorchak, Environ. Pollut.,

11 P. Cardinal, J. C. Anderson, J. C. Carlson, J. E. Low, J. K. Challis, S. A. Beattie, C. N. Bartel, A. D. Elliott, O. F. Montero, S. Lokesh, A. Favreau, T. A. Kozlova, C. W. Knapp, M. L. Hanson and C. S. Wong, Sci. Total Environ., 2014, 482-483, 294-304.

12 X. Li, W. Zheng and W. R. Kelly, Sci. Total Environ., 2013, 445-

13 R. Loos, R. Carvalho, D. C. António, S. Comero, G. Locoro, S. Tavazzi, B. Paracchini, M. Ghiani, T. Lettieri, L. Blaha, B. Jarosova, S. Voorspoels, K. Servaes, P. Haglund, J. Fick, R. H. Lindberg, D. Schwesig and B. M. Gawlik, Water Res., 2013, 47,
14 K. Fent, A. A. Weston and D. Caminada, Aquat. Toxicol., 2006, 76, 122-159.

15 Â. Almeida, R. Freitas, V. Calisto, V. I. Esteves, R. J. Schneider, A. M. V. M. Soares and E. Figueira, Comp. Biochem. Physiol. Part C Toxicol. Pharmacol., 2015, 172-173, 26-35.

16 T. Brodin, J. Fick, M. Jonsson and J. Klaminder, Science, 2013, 339, 814-815.

17 N. Casatta, G. Mascolo, C. Roscioli and L. Viganò, Sci. Total Environ., 2015, 511, 214-222.

18 K. Grabicova, R. H. Lindberg, M. Östman, R. Grabic, T. Randak, D. G. Joakim Larsson and J. Fick, Sci. Total Environ., 2014, 488-489, 46-50.

19 C. M. de Jongh, P. J. F. Kooij, P. de Voogt and T. L. ter Laak, Sci. Total Environ., 2012, 427-428, 70-77.

20 J. Altmann, A. Sperlich and M. Jekel, Water Res., 2015, 84, 5865.

21 M. Klavarioti, D. Mantzavinos and D. Kassinos, Environ. Int., 2009, 35, 402-417.

22 I. Ali, M. Asim and T. A. Khan, J. Environ. Manage., 2012, 113, 170-183.

23 S. M. Lee and D. Tiwari, Appl. Clay Sci., 2012, 59-60, 84-102.

24 R. Guégan, M. Giovanela, F. Warmont and M. Motelica-Heino, J. Colloid Interface Sci., 2015, 437, 71-79.

25 G. Z. Kyzas, J. Fu, N. K. Lazaridis, D. N. Bikiaris and K. A. Matis, J. Mol. Liq., 2015, 209, 87-93.

26 T. Polubesova, D. Zadaka, L. Groisman and S. Nir, Water Res. 2006, 40, 2369-2374.

27 P.-H. Chang, W.-T. Jiang, Z. Li, C.-Y. Kuo, J.-S. Jean, W.-R. Chen and G. Lv, J. Hazard. Mater., 2014, 277, 44-52.

28 A. Mahamat Ahmat, M. Boussafir, C. Le Milbeau, R. Guegan, J. Valdès, M. Guiñez, A. Sifeddine and L. Le Forestier, Mar. Chem, 2016, 179, 23-33.

29 S. Zheng, Z. Sun, Y. Park, G. A. Ayoko and R. L. Frost, Chem. Eng. J., 2013, 234, 416-422.

30 T. Thiebault, R. Guégan and M. Boussafir, J. Colloid Interface Sci., 2015, 453, 1-8.

31 I. Aksu, E. Bazilevskaya and Z. T. Karpyn, GeoResJ, 2015, 7, 113.

32 L. Wu, L. Liao and G. Lv, J. Colloid Interface Sci., 2015, 454, 17.

33 L. Le Forestier, F. Muller, F. Villieras and M. Pelletier, Appl. Clay Sci., 2010, 48, 18-25.

34 A. Jullien, C. Proust, L. Le Forestier and P. Baillif, Appl. Clay Sci., 2002, 21, 143-153.

35 M. Gautier, F. Muller, L. Le Forestier, J.-M. Beny and R. Guegan, Appl. Clay Sci., 2010, 49, 247-254.

36 C. Schummer, O. Delhomme, B. M. R. Appenzeller, R. Wennig and M. Millet, Talanta, 2009, 77, 1473-1482.

37 M. Carballa, G. Fink, F. Omil, J. M. Lema and T. Ternes, Water Res., 2008, 42, 287-295.

38 L. Yang, M. Jin, C. Tong and S. Xie, J. Hazard. Mater., 2013, 244-245, 77-85.

39 P. A. Domenico and F. W. Schwartz, Physical and chemical hydrogeology, Wiley, New York, NY, 2. ed., 1998.

40 F. T. Madsen, Clay Miner., 1998, 33, 109-129.

41 M. Ghayaza, L. Le Forestier, F. Muller, C. Tournassat and J.-M. Beny, J. Colloid Interface Sci., 2011, 361, 238-246.

42 B. Blair, A. Nikolaus, C. Hedman, R. Klaper and T. Grundl, Chemosphere, 2015, 134, 395-401.

43 A. Wick, G. Fink, A. Joss, H. Siegrist and T. A. Ternes, Water Res., 2009, 43, 1060-1074. 
71644 T. A. Ternes, N. Herrmann, M. Bonerz, T. Knacker, H. Siegrist and A. Joss, Water Res., 2004, 38, 4075-4084.

71845 T. X. Bui and H. Choi, Chemosphere, 2010, 80, 681-686.

71946 H. Mansouri, R. J. Carmona, A. Gomis-Berenguer, S. SouissiNajar, A. Ouederni and C. O. Ania, J. Colloid Interface Sci., 2015, 449, 252-260.

47 V. Calisto, C. I. A. Ferreira, J. A. B. P. Oliveira, M. Otero and V. I. Esteves, J. Environ. Manage., 2015, 152, 83-90.

48 M. Hörsing, A. Ledin, R. Grabic, J. Fick, M. Tysklind, J. la C. Jansen and H. R. Andersen, Water Res., 2011, 45, 4470-4482.

49 S. K. Behera, S. Y. Oh and H. S. Park, Int. J. Environ. Sci. Technol., 2012, 9, 85-94.

50 E. Errais, J. Duplay, M. Elhabiri, M. Khodja, R. Ocampo, R. Baltenweck-Guyot and F. Darragi, Colloids Surf. Physicochem. Eng. Asp., 2012, 403, 69-78.

51 J. Gao and J. A. Pedersen, Environ. Sci. Technol., 2005, 39, 9509-9516. 